


\section{Induced sputum in occupational lung diseases}

\section{Educational aims}

I To introduce induced sputum methodology in the field of occupational lung diseases.

I To describe the eosinophil count as a method of monitoring occupational asthma.

I To explain how to use quantitative and qualitative analysis of inhaled particles in hazardous dust exposure.

\section{Summary}

Induced sputum is a particularly promising procedure, since it provides specific information on both the cellular and molecular constituents in inflammation. In the period 1950-1970, sputum cells were examined on stained smears in both research and clinical settings. After their recovery by spontaneous coughing, the cells were used to study lung cancer and respiratory infections, and, later on, to diagnose Pneumocystis carinii pneumonia in patients infected with HIV. The method was widely improved upon by the induction of sputum with aerosol of hypertonic saline, and then extended to become part of the assessment of airway inflammation in bronchial asthma and COPD. However, less attention was given to the use of induced sputum in occupational exposures. This review analyses the value of induced sputum and presents its applications in pulmonary occupational and environmental medicine.

Most of the initial assessments of particulate burden and involvement of inflammatory and structural cells in occupational lung diseases were made in studies using fibreoptic bronchoscopy in conjunction with bronchoalveolar lavage (BAL) [1-3]. The relative invasiveness of this technique, however, has restricted the use of bronchoscopy to a limited number of specialised centres, and hampered its development into a practical and suitable tool for screening programmes, exposure evaluation or repeated follow-up of workers exposed to hazardous dust in large populations.

There is an on-going search for other noninvasive techniques that can either substitute

\section{E. Fireman $n^{1,3}$ \\ Y. Lerman ${ }^{2,3}$}

${ }^{1}$ Institute of Pulmonary and Allergic Diseases, National Service for Interstitial Lung Diseases Tel-Aviv Sourasky Medical Center, ${ }^{2}$ Occupational Health Center Clalit Health Senvices, and ${ }^{3}$ Dept of Epidemiology and Preventive Medicine, Sackler Faculty of Medicine, Tel-Aviv University, Tel-Aviv, Israel.

\section{Correspondence}

E. Fireman

Institute of Pulmonary and

Allergic Diseases

Tel-Aviv Sourasky Medical Center

6 Weizman Street

Tel-Aviv 64239

Israel

Fax: 97236974601

E-mail:

fireman@tasmc.health.gov.il

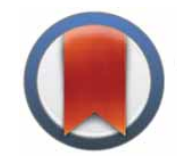

CrossMark $\leftarrow$ click for updates

\section{Glossary \\ Al: Aluminium \\ Si: Silica \\ Ti: Titanium \\ Fe: Iron \\ Ca: Calcium \\ Mg: Magnesium \\ Ag: Silver \\ Cu: Copper \\ Hg: Mercury \\ Zn: Zinc}


or provide complementary information when there are clinical contraindications for performing bronchoscopy. One technique involves nitric oxide, which arises in differing amounts from the airway and alveolar compartments. It was first detected in exhaled breath more than one decade ago and has since been investigated as a noninvasive means of assessing lung inflammation [4]. Several inflammatory mediators have been identified in the exhaled breath condensate that is formed by breathing through a cooling system [5], but the only non-invasive method which allows direct study of soluble mediators $[6,7]$ together with cellular components [8] in the lung is the examination of induced sputum (IS).

IS is now being widely used in medicine. In the period 1992-2004, $>650$ papers were published on the application of IS in the diagnosis and management of asthma, and 200 on its use in chronic obstructive pulmonary disease (COPD) and chronic bronchitis. However, much less attention has been paid to the application of this technique in occupational and environmental exposures.

The present review demonstrates the usefulness of sputum analysis to diagnose, assess and monitor occupational lung disorders. The use of IS will be described in both obstructive airway disease (IS and occupational asthma) and in interstitial lung diseases (IS in occupational exposure to hazardous dust).

\section{Obstructive airway disease: \\ IS and occupational asthma}

Occupational asthma (OA) is defined as "a disease characterised by variable airflow limitation and/or airway hyperresponsiveness, due to causes and conditions attributable to a particular occupational environment and not to stimuli encountered outside the workplace" [9]. Diagnosing OA continues to be a challenge and it is often difficult to distinguish it from pre-existing asthma that has been worsened by conditions in the workplace. The current gold-standard method is to perform a specific inhalation challenge with the suspected agent [10], but this test is expensive and time consuming, and it is available in only a few specialised centres worldwide. The use of changes in peak expiratory flow (PEF) rates and bronchial responsiveness to pharmacological agents is questionable, as the criteria for interpretation are still controversial, since they do not have optimal sensitivity and specificity, and bear a number of pitfalls, such as low compliance, potential falsification of results and underestimation of changes in airway calibre [11]. Methacholine- and histamine-challenge tests, which are methods for measuring non-specific bronchial hyperresponsiveness, have been proposed for the evaluation of $\mathrm{OA}$, but the addition of serial measures of airway responsiveness to methacholine or histamine has also been advocated to document work-related changes [12].

The eosinophilic inflammatory process involved in asthma has been widely investigated in recent years, and the results from these studies have led to the diagnostic practice of identifying eosinophils in sputum specimens. Methacholine airway responsiveness and sputum differential eosinophil counts have emerged as the most useful objective tests for identifying patients with mild asthma [13]. One decade ago, it was shown that high eosinophil counts can be detected in the IS of asthmatic isocyanate-sensitised subjects [14]. In addition, many other lines of evidence have since shown that the eosinophil is a useful marker for monitoring OA. The percentage of sputum eosinophils increases after exposure to occupational agents in the laboratory when compared with baseline, and significant changes are seen in sputum eosinophils when workers are exposed to a sensitiser at their workplace when compared with periods away from the workplace [15]. Moreover, it has been shown that the specificity and sensitivity of monitoring PEF in workers are significantly increased when eosinophil counts are added in sputum samples [16]. Failure of symptoms to improve after exposure cessation has also been shown to be associated with persistent airway inflammation, as demonstrated by high counts of eosinophils in sputum [17].

In one study, PARKet al. [18] measured soluble mediators in workers exposed to isocyanates, and demonstrated that exposure to toluene diisocyanate leads to overproduction of matrix metalloproteinase (MMP)- 9 , which may induce airway inflammation and remodelling, and then contribute to persistent asthmatic symptoms. LEMIERE et al. [19] recently reported that the neutrophilia observed after exposure to isocyanates is likely to be related to the release of leukotriene (LT)B4, probably enhanced by the increased expression of LTB4 receptor (BLT1) on neutrophils, as well as by the release of interleukin-8. The significance of the increase of CysLT1 receptor expression on neutrophils is unknown and needs further investigation. 


\section{Interstitial lung disease: IS in occupational exposure to hazardous dust}

\section{Exposure assessment}

Several investigators have shown the relevance of asbestos bodies in spontaneous sputum when compared to BAL. Sputum analysis for asbestos bodies has been shown to be an insensitive method for assessing lung asbestos burden, one much less sensitive than BAL fluid analysis. However, a sputum sample positive for asbestos bodies is suggestive of a high lung asbestos burden, since a correlation has only been found in workers with high levels of exposure [20, 21]. Although another group of investigators found agreement of asbestos body detection in only $56.8 \%$ of their cases, they concluded that the two methods (BAL+IS) were complementary, since both are useful in increasing the probability of detection [22].

IS has been found to be useful in screening for occupational lung cancer. In a study by MAREK et al. [23], semi-automated sputum cytometry appeared to be sensitive and reliable for the detection of malignant changes in the tracheobronchial mucosa in a limited number of patients with occupational radon or asbestos exposure. Together with conventional cytology, the authors stated that it would be reasonable to test the validity of the combined methods in a large-scale feasibility study of early lung cancer detection.

Evaluation of silica- and hard metal-exposed workers has revealed that BAL and IS specimens yield similar quantitative and qualitative results in terms of the number of particles present in the samples and the chemical analysis of the particles [24]. The qualitative analysis of chemical particles was performed by scanning electron microscope (SEM) (table 1), while the quantitative analysis was done using a Cis-100 analyser (Ankersmid, Yokneam, Israel; figure 1), which allows rapid analysis using minute quantities of biological material. The results showed that $\sim 70 \%$ of particles internalised by macrophages or epithelial cells, present in IS as well as in BAL samples, were $<2.5 \mu \mathrm{m}$. The US Environmental Protection Agency is currently proposing regulations that will target particles whose aerodynamic diameters are $<2.5 \mu \mathrm{m}$. IS measurements may also enable investigation of the remaining $\geq 30 \%$ of the particles, especially those with diameters of

\section{Table 1 Polarised light and mineralogical studies of cells recovered by BAL and IS in asbestos workers and silica and hard-metal workers}

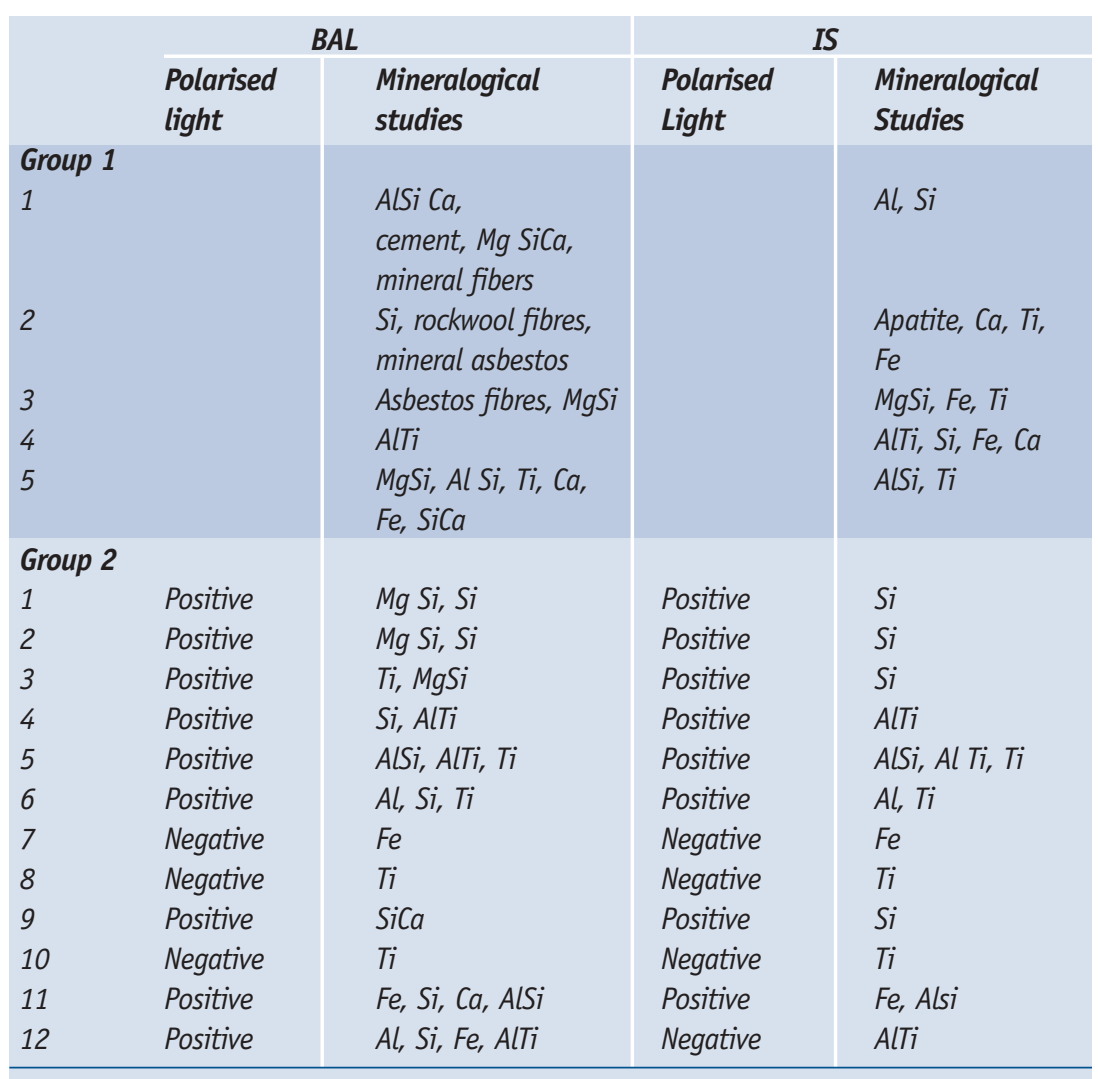

Table modified with permission from [24].

4-5 $\mu \mathrm{m}$, which are deposited in the lower lung fields. These particles represent the largest fraction of the weight of the dust that enters the lower lung fields. Following on from these findings, the hypothesis that the quantitative and qualitative analysis of particles recovered by IS can serve as a biological monitoring method in the periodic health examinations of healthy workers exposed to hazardous dusts in addition to the traditional occupational parameters of past history and environmental measurements has been proposed. This screening would be parallel to the biological

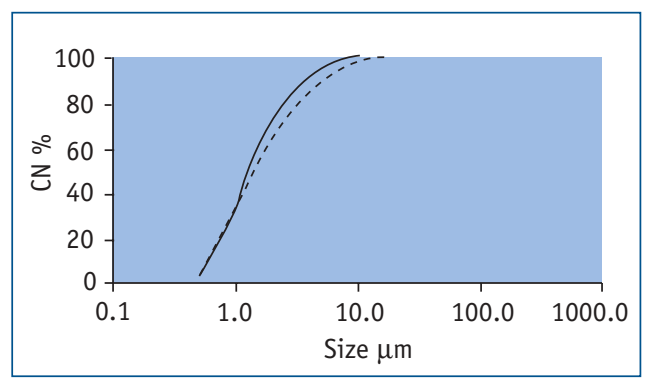

Figure 1

Quantitative analysis of particles in one representative subject using the Cis-100 Analyser. --: the spectrum of particles recovered by $B A L ;$ - - - : the spectrum of particles recovered by IS. CN: confidence number. Figure modified with permission from [24]. 
monitoring of workers exposed to toxic agents, such as metals (e.g. lead, cadmium) and solvents (e.g. toluene, trichloroethane), the levels of which can be estimated in an individual by measuring the chemical or its metabolite in blood, urine or exhaled air [25].

In a fatal case of accelerated silicosis with a component of mixed dust pneumoconiosis in a young hard-metal grinder [26], good agreement was demonstrated between the BAL and IS findings, with the polarising light microscopic studies of both BAL and IS showing polarising particles typical for silica.

It should be noted that the studies above were performed in optimal clinical laboratory conditions. The use of the presented method for large-scale screening of workers would necessitate the performance of sputum induction at the workplace, since transporting these workers to a laboratory could cause unacceptable inconvenience in the work schedule.

In this context, the IS method has been applied in the workplace itself, during routine periodic health examinations of foundry workers. In this case, the objectives were to assess whether the distribution of particle size in IS specimens was different between exposed and non-exposed workers, whether smoking was a confounder of the association, and whether there was a correlation between the distribution of particle size and the results of the workers' pulmonary function tests. The results showed that there were significant differences in the proportion of particles with diameters $>2 \mu \mathrm{m}$ between the exposed and non-exposed groups, as well as in the proportion of particle with diameters $>5 \mu \mathrm{m}$. There was a positive correlation between the proportion of particles $>5 \mu \mathrm{m}$ and the forced expiratory volume in one second $\left(\mathrm{FEV}_{1}\right) /$ forced vital capacity

Table 2 Correlation between particle size distribution and pulmonary function tests

\begin{tabular}{lllll}
$\begin{array}{l}\text { Particle size } \\
\text { 0-2 } \mu \text { m diameter }\end{array}$ & Workers & \% FVC & $\%$ FEV 1 & FEV1/FVC \\
& All groups & $\begin{array}{l}r=-0.13 \\
p=N S\end{array}$ & $\begin{array}{l}r=-0.05 \\
p=N S\end{array}$ & $\begin{array}{l}r=-0.21 \\
p=N S\end{array}$ \\
$2-5 \mu$ m diameter & All groups & $\begin{array}{l}r=-0.14 \\
p=N S\end{array}$ & $\begin{array}{l}r=-0.09 \\
p=N S\end{array}$ & $r=-0.15$ \\
& & $p=N S$ \\
$>5 \mu$ m diameter & All groups & $r=-0.52$ & $r=-0.07$ & $r=0.31$ \\
& & $p=0.05$ & $p=N S$ & $p=0.02$ \\
$>5 \mu m$ diameter & Casting & $r=-0.09$ & $r=-0.09$ & $r=0.47$ \\
& non-smokers & $p=N S$ & $p=N S$ & $p=0.02$ \\
\hline
\end{tabular}

$r$ : Pearson correlation coefficients were used as a measure of association between particle diameter size and spirometry parameters; $p$-value: $<0.05$ was considered as indicative of a significant statistical difference (NS: non-significant).
(FVC) ratio for all 54 workers, and a significant correlation for non-smokers (table 2) [27].

\section{Evaluation and diagnosis: case series}

IS can also assist in the evaluation and diagnosis of suspected occupational lung diseases [28]. In this study, the three patients who underwent IS included a miner with silicosis, a dental technician with berylliosis and a teacher who suffered from undefined interstitial fibrosis, in whom a high burden of calcium sulphate and silica was documented.

The miner was a 73-year-old non-smoker male who had been referred to the laboratory for sputum analysis due to progressive shortness of breath. He had immigrated to Israel after World War II, and had been a forced labourer under Nazi

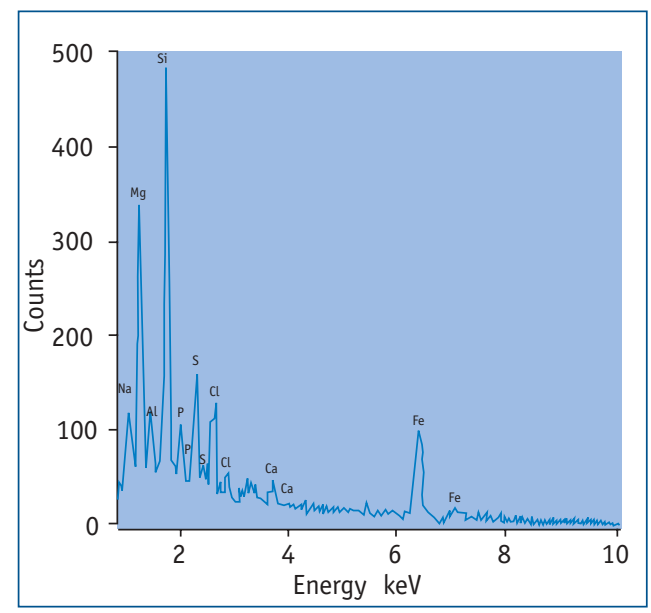

Figure 2

X-ray spectrum of representative particles of asbestos fibres.

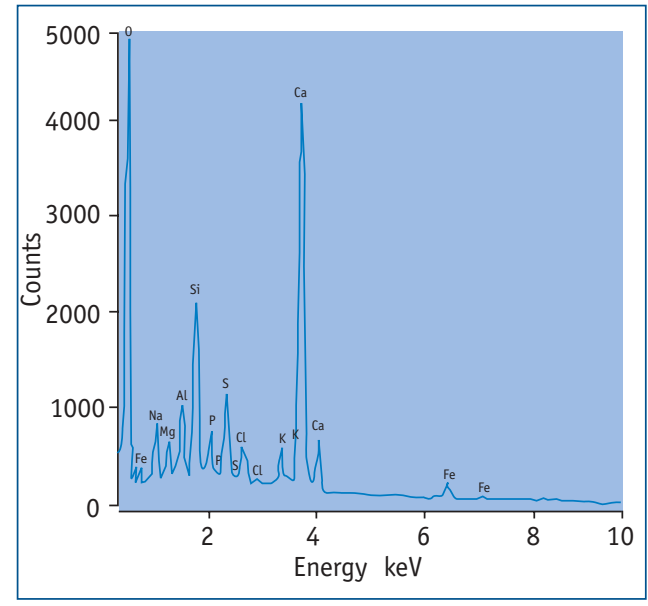

Figure 3

$X$-ray spectrum of representative particles of calcium sulphate $\left(\mathrm{CaSO}_{4}\right)$. 
captivity in the mining industry in Silesia, working for 12 hours every day for 7 months. The work was conducted in a heavily dusty environment and the labourers were not provided with any protective equipment. The patient's chest computerised tomography showed diffuse interstitial fibrosis. Pulmonary function testing revealed a restrictive pattern with a decrease in diffusion capacity. Chemical analysis of his sputum by SEM-energydispersive system (EDS) and petrographic microscopy demonstrated abundant particles $(1-4.5 \mu \mathrm{m})$ of clay minerals, quartz, aluminium and asbestos fibres (figure 2).

The dental technician was a 27-year-old nonsmoker female diagnosed by open lung biopsy as having sarcoidosis. Due to her past occupational history, she was referred to the clinic for IS and to the beryllium lymphocyte proliferation test (BeLPT) to rule out a possible misdiagnosis of silicosis/berylliosis. Chemical analysis of the sputum by SEM-EDS and petrographic microscopy showed abundant particles $(1.6-2.5 \mu \mathrm{m})$ of clay minerals, i.e. AlSiFe, AlSiCa, $\mathrm{Al}_{2} \mathrm{Si}_{4}(\mathrm{OH})_{2}$, quartz $\left(\mathrm{SiO}_{2}\right)$ and barite $\left(\mathrm{BaSO}_{4}\right)$. The BeLPT showed positive results.

The third case was a 46-year-old non-smoker female, employed full-time as a teacher for 24 years, using blackboard chalks of different types as part of the daily course of her work. There were
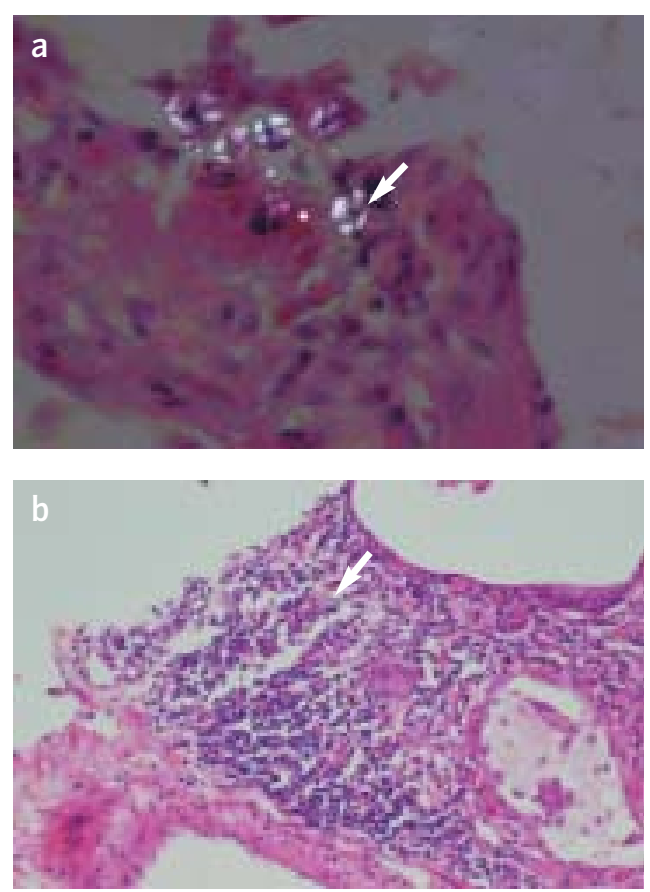

Figure 4

Typical structures (Malte Cross) of polarising bodies (arrow in a) are shown and in the fibrotic tissue (arrow in b).

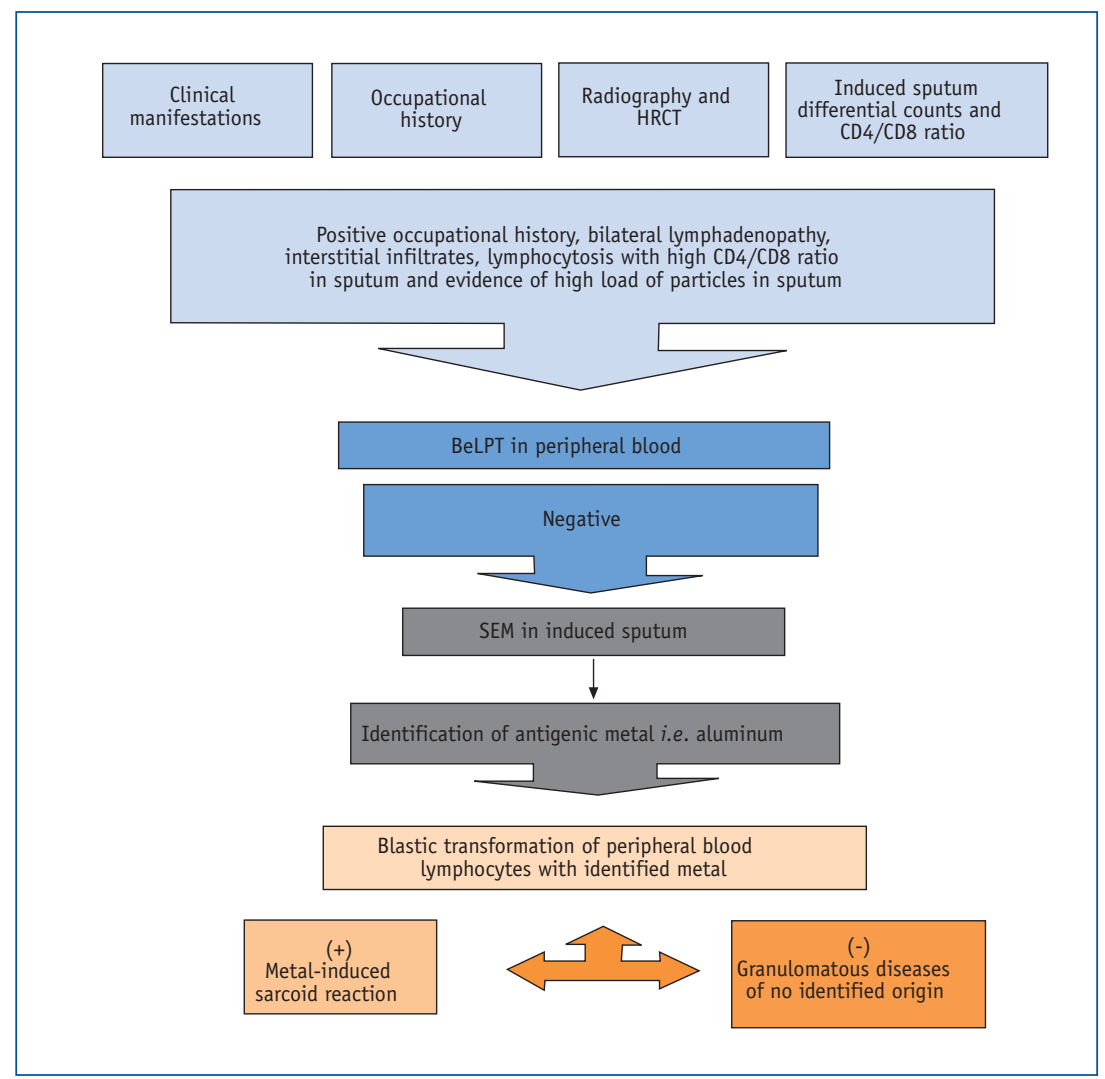

no other exposures to potentially hazardous materials. The lung biopsy had showed non-specific interstitial pneumonia with some areas of unusual interstitial pneumonia in the first stages. Due to worsening of functional parameters, she underwent lung transplantation. Chemical analysis by SEM-EDS and petrographic microscopy were performed in IS and tissue biopsy, and revealed that the most abundant particles (1-8 $\mathrm{mm}$ ) were those of calcium sulphate $\left(\mathrm{CaSO}_{4}\right)$, silica $\left(\mathrm{SiO}_{2}\right.$ ) and silicates ( $\mathrm{SiCaFe}$ and AlSi) (figure 3). $A$ representative polarising foreign structure is shown in figure $4 a$ and in the fibrotic tissue in figure $4 b$.

In another case, a sarcoid-like lung granulomatous was diagnosed in a patient exposed to aluminium powder [29]. The flowchart of the work-up performed, focusing upon the role of the mineralogical analysis of IS as the key to the identification of the metal whose antigenic properties caused the granulomatous response, is presented in figure 5. T-cell subsets recovered from IS disclosed a helper T-lymphocyte alveolitis, and transbronchial biopsies showed sarcoid-like epithelioid granulomata. Peripheral blood lymphocytes exhibited blastic transformation in the presence of soluble aluminium compounds. The final diagnosis was sarcoid-like granulomatousinduced aluminium disease.

\section{Figure 5}

Flow chart of a non-invasive work-up for the identification of an occupational agent. BeLPT: beryllium lymphocyte proliferation test. 


\section{Figure 6}

Intracellular phagocytosed particles in a Giemsa-stained cytospin preparation from the IS sample of a New York fire fighter exposed to World Trade Center dust. a) Single macrophage with intracellular particles and two adjacent lymphocytes. b) Mixed cell population with macrophages and intracellular particles.

\section{Figure 7}

$X$-ray spectra of representative particles identified as a) $\mathrm{Cu}, \mathrm{Hg}$ and $\mathrm{Ag}$, and b) $\mathrm{Zn}$ in a New York fire fighter exposed to World Trade Center dust.
Table 3 Differential counts, MMP-9 levels and particle size distribution in New York City fire fighters analysed according to cumulative exposure

\begin{tabular}{|lccl|}
\hline & $<10$ days & $\geq 10$ days & $p$-values \\
Duty years & $15.6 \pm 8.3$ & $17.6 \pm 8.6$ & 0.78 \\
Macrophages \% & $31.1 \pm 13.7$ & $38.4 \pm 16.5$ & 0.18 \\
Neutrophils \% & $44.2 \pm 16.5$ & $55.7 \pm 15.2$ & 0.05 \\
Lymphocytes \% & $11.6 \pm 7.0$ & $12.9 \pm 6.8$ & 0.59 \\
Eosinophils \% & $1.5 \pm 1.9$ & $4.4 \pm 5.2$ & 0.04 \\
Particles $>2 \mu \mathrm{m} \%$ & $32.3 \pm 13.7$ & $38.6 \pm 17$ & 0.48 \\
Particles $>5 \mu \mathrm{m} \%$ & $7.8 \pm 3.3$ & $9.3 \pm 7.1$ & 0.28 \\
MMP-9 $\mathrm{ng}$ per $\mathrm{mL}$ & $1.73 \pm 0.98$ & $2.7 \pm 4.0$ & 0.36 \\
\hline
\end{tabular}

\section{Application of IS in a unique exposure event}
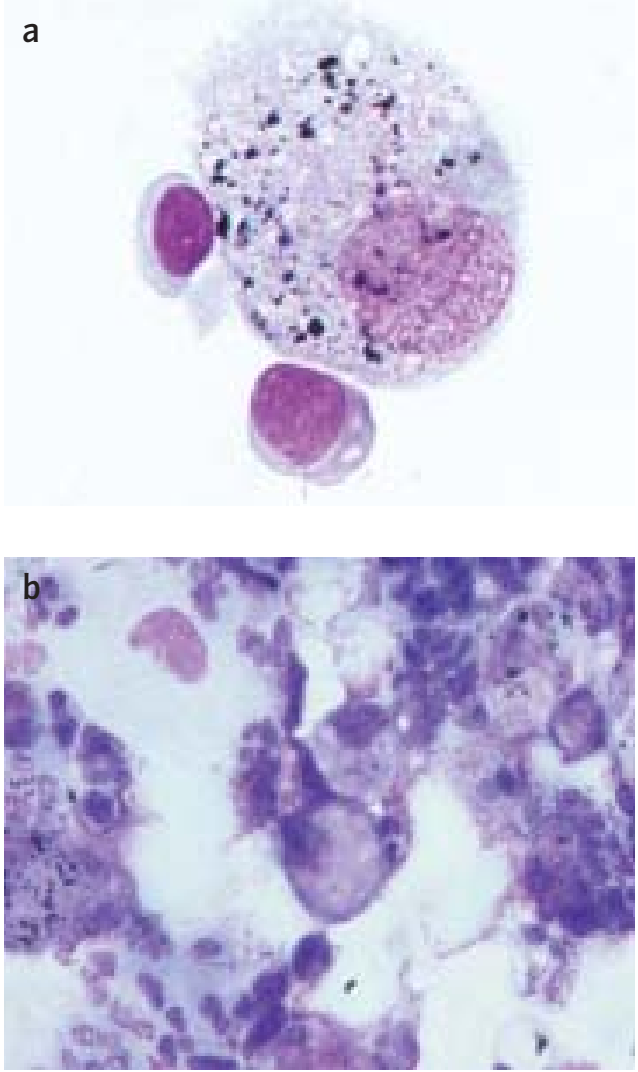

After the disaster at the World Trade Center in New York (USA), a study was preformed to determine whether IS from highly exposed New York fire fighters who had been caught in the dust cloud during the collapse on September 11,2001, demonstrated a unique pattern of inflammation and particulate matter deposition when compared with World Trade Center dust 10 months post-collapse. It was found that IS fire fighter differential cell counts differed from healthcare worker controls $(p<0.05)$, but not from fire fighters in Tel Aviv [30]. Neutrophil and eosinophil percentages increased with greater intensity of World Trade Center exposure ( $<10$ workdays or $\geq 10$ workdays; neutrophils $p=0.046$; eosinophils $p=0.038$ ) [30]. MMP-9 levels positively correlated to neutrophil counts $(p=0.002 ; r=0.449)$ (table 3). The particles were larger and more irregularly shaped in the exposed New York group (1-50 um; Zn, Hg, Au, Sn, Ag) than in the Tel Aviv fire fighters $(1-10 \mu \mathrm{m}$; silica, clays) (figures 6 and 7).

In conclusion, the authors suggest the integration of IS technology to the already well-established criteria [31] for the diagnosis of occupational lung diseases which include:

1. An exposure history that suggests a substantial risk of the condition.

2. Imaging findings consistent with the condition.

3. The absence of any good reason to believe that the imaging findings are the result of some other condition.

\section{Conclusions}

IS is a safe non-invasive technique that is opening a new window in the field of research and diagnosis of occupational diseases of the lung. 


\section{Methodology}

\section{How to induce sputum}

The technique of sputum induction consists of inhaling an aerosol of saline (either normal or hypertonic) over different time periods. The aim of IS is to collect an adequate sample of secretions from the lower airways in subjects who do not produce sputum spontaneously. Ultrasonic nebulisers are recommended, since other types do not usually yield a sufficient output of saline aerosol (figure 8). The current consensus is that an output of approximately $1 \mathrm{~mL}$ per minute is sufficient to achieve a high success rate. Pre-treatment with the short-acting $\beta_{2}$-agonist salbutamol $(200 \mu \mathrm{g})$, delivered via a standard metered-dose inhaler is generally used. It is now recommended that induction be conducted with a $4.5 \%$ saline solution as standard, because it is commercially available, effective and generally well tolerated for a duration of 15-20 minutes. Fresh sterile saline solutions should be used. Patients may be asked to stop inhalation at set intervals in order to cough up sputum or, alternatively, to stop inhalation only when they feel the urge to cough.

\section{How to process samples}

There are two techniques in current use. One involves collecting and analysing the more viscid portions of mucus (plugs) extracted from a sputum sample, and the other involves collecting and analysing the entire sample, including saliva. Both methods have been described and compared in detail. It was found that the selected sputum procedure provides more viable cells than the entire sample examination, but both methods are useful in terms of eosinophils and eosinophil cationic protein content for differentiating asthmatics from healthy subjects. It is recommended that sputum be processed as soon as possible or within 2 hours in order to ensure optimum cell counting and staining. Complete homogenisation is important and can be achieved by the use of dithiothreitol and dithioerythritol to break the disulphide bonds in mucin molecules, allowing cells to be released. Homogenisation is possible by using a shaking water bath at $37^{\circ} \mathrm{C}$ and removing the sample periodically for brief aspiration. Filtration through a 48-um nylon mesh is commonly used to remove mucus and debris, and is strongly recommended. Centrifugation is necessary to separate sputum cells from the fluid phase. Preparation of cytospins with an optimum

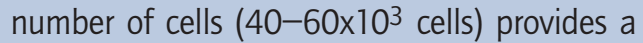
more accurate estimate of cell distribution than smears. Cytospin staining for differential cell counts can be achieved using either Wright's or Giemsa stains. This allows accurate characterisation of cells on the basis of their staining and morphology. The differential cell count is determined by counting a minimum of 400 nonsquamous cells and is reported as the relative numbers of eosinophils, neutrophils, macrophages, lymphocytes and bronchial epithelial cells, expressed as a percentage of total nonsquamous cells. The percentage of squamous cells should always be reported separately.

\section{How to process samples for occupational assessment}

After separation of the plugs and viscous materials, all fractions of IS should be preserved in 10\% formalin and stored at $4^{\circ} \mathrm{C}$ until analysis of mineral particles. Samples containing both extracellular and intracellular particles can be used for the SEM analysis. The samples are treated with $14 \%$ formamide solution and filtered through a 0.8-um carbon-coated Nuclepore filter. Particles with a diameter $>0.4 \mu \mathrm{m}$ are analysed by a JEOL 840 SEM (JEOL Ltd, Hertfordshire, UK) equipped with a Link 10,000 energy-dispersive system (EDS; Link Oxford Analytical Instruments, Oxford, UK). The spectrometer of the EDS system separates the elements according to energy rather than wavelength and the petrographic microscope identifies minerals. The size and shape of the particles from the rich cell fraction of the processed plugs can be analysed by the Cis 100 analyzer (Ankersmid, Yokneam, Israel) or Particle Size Analyzer (Malvern Instruments Ltd, Worcestershire, UK). Measurements are performed on two drops of a suspension of sputum cells ( $1 \times 10^{6}$ cells per $\mathrm{mL}$ ) introduced into a quartz cuvette containing stirred water.

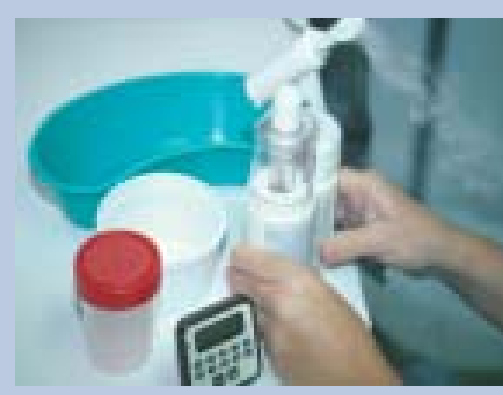

Figure 8

An example of an ultrasonic nebuliser. 


\section{Educational questions}

1. What is IS?

2. How is OA defined and what is the best method to distinguish it from pre-existing asthma?

3. Environmental monitoring versus biological monitoring: what are they and how can they be correlated to produce comprehensive findings?

4. How can IS be introduced in the assessment of occupational diseases of the lung?

\section{References}

1. Davidson AG, Haslam PL, Corrin B, et al. Interstitial lung diseases and asthma in hard metal workers: bronchoalveolar lavage, ultrastructure, and analytical findings and results of bronchial provocation tests. Thorax 1983; 38: 119-128.

2. De Vuyst $P$, Dumortier $P$, Gevenois PA. Analysis of asbestos bodies in BAL from subjects with particular exposures. Am $J$ Ind Med 1997; 31: 699-704.

3. Mutsaers SE, Harrison NK, MCAnulty RJ, Liao JY, Laurent GJ, Musk AW. Fibroblast mitogens in bronchoalveolar lavage (BAL) fluid from asbestos-exposed subjects with and without clinical evidence of asbestosis: no evidence for the role of PDGF, TNF- $\alpha$, IGF-1, or IL-1ß. J Pathol 1998; 185: 199-203.

4. George SC, Hogman M, Permutt S, Silkoff PE. Modeling pulmonary nitric oxide exchange. J Appl Physiol 2004; 96: 831-839.

5. Montuschi P, Barnes PJ. Analysis of exhaled breath condensate for monitoring airway inflammation. Trends Pharmacol Sci 2002; 23: 232-237.

6. Pin I, Gibson PG, Kolendowicz $R$, et al. Use of induced sputum cell counts to investigate airway inflammation in asthma. Thorax 1992; 47: 25-29.

7. Kim CK, Hagan JB. Sputum tests in the diagnosis and monitoring of asthma. Ann Allergy Asthma Immunol 2004; 93: 112-122.

8. Keatings V, Leigh R, Peterson C, Shute J, Venge P, Djukanovic R. Analysis of fluid-phase mediators. Eur Respir J 2002; 20: 24S-39S.

9. Bernstein IL, Bernstein DI, Chan-Yeung M, Malo JL. Definition and classification of asthma. In: Berstein IL, Chan-Yeung M, Malo JL, Bernstein DI, eds. Asthma in the Workplace. 2nd Edn. New York, Marcel Dekker, 1999; pp. 1-3.

10. Tarlo SM, Boulet LP, Cockcroft DW, et al. Directives de la Société canadienne de thoracologie pour l'asthme. [Professional Canadian Thoracic Society guidelines for occupational asthma.] Can Respir J 1998; 5: 397-410.

11. Moscato G, Godnic-Cvar J, Maestrelli P, Malo J, Burge P, Coifman R. Statement on self-monitoring of peak expiratory flows in the investigation of occupational asthma. J Allergy Clin Immunol 1995; 96: 295-301.

12. Chan-Yeung M, Malo JL, Tarlo SM, et al. Proceedings of the first Jack Pepys occupational asthma symposium. Am J Respir Crit Care Med 2003; 167: 450-471.

13. Hunter CJ, Brightling CE, Woltmann G, Wardlaw AJ, Pavord ID. A comparison of the validity of different diagnostic tests in adults with asthma. Chest 2002; 121: 1051-1057.

14. Maestrelli $P$, Calcagni PG, Saetta M, Man A, Ribak J, Lerman Y. Sputum eosinophilia after asthmatic responses induced by isocyanates in sensitized subjects. Clin Exp Allergy 1994; 24: 29-34.

15. Lemiere $C$. The use of sputum eosinophils in the evaluation of occupational asthma. Curr Opin Allergy Clin Immunol 2004; 4: 81-85.

16. Girard F, Chaboillez S, Cartier A, et al. An effective strategy for diagnosing occupational asthma: use of induced sputum. Am J Respir Crit Care Med 2004; 170: 845-850.

17. Maghni K, Lemiere C, Ghezzo H, Yuquan W, Malo JL. Airway inflammation after cessation of exposure to agents causing occupational asthma. Am J Respir Crit Care Med 2004; 169: 367-372.

18. Park HS, Kim HA, Jung JW, et al. Metalloproteinase-9 is increased after toluene diisocyanate exposure in the induced sputum from patients with toluene diisocyanate-induced asthma. Clin Exp Allergy 2003; 33: 113-118.

19. Lemiere C, Pelissier S, Tremblay C, et al. Leukotrienes and isocyanate-induced asthma: a pilot study. Clin Exp Allergy 2004; 34: 1684-1689.

20. Teschler H, Thompson AB, Dollenkamp R, Konietzko N, Costabel U. Relevance of asbestos bodies in sputum. Eur Respir J 1996; 9: 680-686.

21. Capellaro E, Chiesa A, Villari S, Bontempi S, Sulotto F, Scansetti G. Asbestos bodies in bronchoalveolar lavage fluid and sputum. Med Lav 1997; 88: 99-107.

22. Paris C, Galateau-Salle F, Creveuil $C$, et al. Asbestos bodies in the sputum of asbestos workers: correlation with occupational exposure. Eur Respir J 2002; 20: 1167-1173.

23. Marek W, Kotschy-Lang N, Muti A, et al. Can semi-automated image cytometry on induced sputum become a screening tool for lung cancer? Evaluation of quantitative semi-automated sputum cytometry on radon-and uranium-exposed workers. Eur Respir J 2001; 18: 942-950.

24. Fireman E, Greif J, Schwarz Y, et al. Assessment of hazardous dust exposure by BAL and induced sputum. Chest 1999; 115: $1720-1728$.

25. Rosenberg G, Harrison R. Biological Monitoring. In: Occupational and Environmental Medicine. La Dou J, ed. 2nd Edn. New York, Appleton and Lange, 1997; pp. 637-646.

26. Cohen C, Fireman E, Ganor E, Man A, Ribak J, Lerman Y. Accelerated silicosis with mixed-dust pneumoconiosis in a hardmetal grinder. J Occup Environ Med 1999; 41: 480-485.

27. Lerman Y, Segal B, Rochvarger M, Weinberg D, Kivity 0, Fireman E. Induced-sputum particle size distribution and pulmonary function in foundry workers. Arch Environ Health 2003; 58: 565-571.

28. Lerman $Y$, Schwarz $Y$, Kaufman G, Ganor E, Fireman E. Case series: use of induced sputum in the evaluation of occupational lung diseases. Arch Environ Health 2003; 58: 284-289. 
29. Fireman E, Goshen M, Ganor E, Spirer Z, Lerman Y. Induced sputum as an additional tool in the identification of metalinduced sarcoid-like reaction. Sarcoidosis Vasc Diffuse Lung Dis 2004; 21: 152-156.

30. Fireman EM, Lerman Y, Ganor E, et al. Induced sputum assessment in New York City firefighters exposed to World Trade Center dust. Environ Health Perspect 2004; 112: 1564-1569.

31. Parkes RW. Occupational Lung Disorders. 3rd Edn. Oxford, Butterworth-Heinemann, 1994; p. 312.

\section{Suggested answers}

1. IS is a non-invasive alternative way of obtaining secretions from the lower airways in order to study the presence and nature of cells and inflammatory mediators present in the airways, as well as their changes during the course of the disease or as a result of treatment.

2. OA is defined as "a disease characterised by variable airflow limitation and/or airway hyperresponsiveness due to causes and conditions attributable to a particular occupational environment and not to stimuli encountered outside the workplace ". It is often difficult to distinguish it from pre-existing asthma that has worsened because of conditions in the workplace. The current gold-standard method is to perform a specific inhalation challenge.

3. Environmental monitoring is a repetitive measurement of specific ecological phenomena in order to quantify the effect of the project on the surrounding environment, while biological monitoring is the analysis of body substances, such as blood or urine, to determine the extent of hazardous material absorption or accumulation. Both environmental and biological measurements are often used in exposure or risk assessments. Environmental measurements are an excellent means for evaluating regulatory compliance, but the models used to estimate body burden from these measurements are complex. Unless all possible routes of exposure (i.e. inhalation, dermal absorption, ingestion) are evaluated, exposure to a toxicant can be underestimated. To circumvent this problem, measurements of the internal dose of a toxicant in blood, serum, urine or tissues can be used singularly or in combination with environmental data for exposure assessment.

4. IS is as a reliable tool as BAL for measuring particle size distribution, chemical composition analysis of particles bySEM and differential cell counts, including CD4/CD8T-cell subsets identification, in the assessment of occupational lung diseases. In addition, IS adds a new dimension to the conventional diagnostic approach of occupational lung diseases. As described in this manuscript, IS emerges as being a potentially important tool for refining the assessment of exposure of toxic substances, the analysis of which has thus far been based solely on occupational history and environmental monitoring.

\section{Suggested further reading}

An Atlas of Induced Sputum: an Aid for Research and Diagnosis. Djukanovic R, Sterk PJ, eds. London, The Parthenon Publishing Group, 2003.

Induced sputum: opening a new window to the lung. Sarcoidosis Vasc Diffuse Lung Dis 2001; 18 : 263-271.

Induced sputum. Eur Respir J 2002; 20: Suppl. 37. 